\title{
Polymorphism in the promoter of TLR4 gene by PCR-RFLP and its association with somatic cell score in Chinese Holstein
}

Zhixiong Li', Huilin Zhang', Hongliang Wang', Ling Chen', Lijun Wang1, Xiaolin Liu', Ailong Song ${ }^{2}$ and Caixia $\mathrm{Ru}^{2}$

${ }^{1}$ College of Animal Science and Technology, Northwest A\&F University; Shaanxi Key Laboratory of Agricultural Molecular Biology, Shaanxi, China, ${ }^{2}$ Animal Husbandry Company, Xi'an Modern Agriculture Comprehensive Development Corporation, Shaanxi, China

\begin{abstract}
The objective of this study was to examine the effect of the polymorphism in the promoter of toll-like receptor 4 (TLR4) on mastitis and milk production traits. Two novel single nucleotide polymorphisms (SNPs) G-1539A before 5'-upstream region and G+265C in the 5'-UTR of TLR4 gene were detected, and genetic association analysis was applied on 421 Chinese Holstein cows. The statistical analysis indicated that two SNPs was significantly associated with 305 Days milk yield $(P<0.05)$ and somatic cell score $(S C S)$ respectively $(P<0.01)$. Our results provide evidence that polymorphisms in the promoter of $T L R 4$ are associated with milk production traits and SCS, and may be used as a possible candidate for marker-assisted selection and management in Holstein cattle breeding program.
\end{abstract}

Keywords: promoter, SNP, PCR-RFLP, Chinese Holstein, TLR4

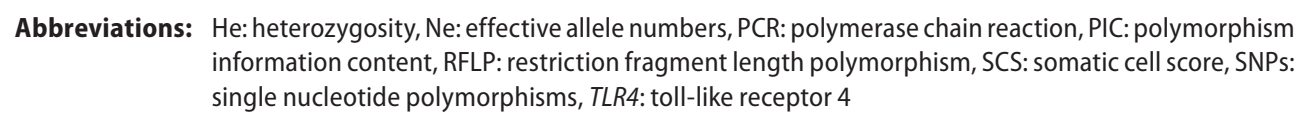




\section{Introduction}

Bovine mastitis, defined as "an inflammation of the mammary gland«, is generally considered the most frequent and costly disease of dairy cattle. Financial losses due to mastitis occur for animals experiencing both subclinical and clinical disease. Losses resulting from clinical mastitis are usually apparent and consist of discarded milk and transient reductions in milk yield (Ruegg 2003). Additional losses include the risk of antibiotic residues and culling or death of affected animals (Ruegg 2003). Subclinical mastitis is the most economically important form of mastitis because of long-term reductions in milk yield (Seegers et al. 2003). The disease cost to the dairy industry was 1.5 billion $€$ annually in the Europe (Seegers et al. 2003). This is due to increased involuntary culling, therapeutic costs, reduced milk yield and changes in milk composition.

Bovine TLR4 gene was discovered in 2003 and mapped to the distal end of BAT8 (White et al. 2003). TLR4 has been testified as a candidate gene for resistance to mastitis using quantitative real-time polymerase chain reaction (PCR) and the association analysis between single nucleotide polymorphisms (SNP) and traits (Goldammer et al. 2004, Werling et al. 2003). The objective of the present study was to explore genetic variants in the promoter of TLR4 gene and analyze the association between SNP and milk production traits and mastitis.

\section{Material and methods}

\section{Animal samples}

The blood samples of 421 multiparous Chinese Holstein cattle at Xi'an Dairy Farm were collected from the jugular vein. All experimental protocols and animal care were performed according to authorization granted by the Chinese Ministry of Agriculture. Each blood sample was placed in a tube with acid-citrate-dextrose anticoagulant for genomic DNA extraction following the standard procedures. The DNA content was estimated spectrophotometrically, and the genomic DNA was diluted to $50 \mathrm{ng} / \mu \mathrm{l}$. DNA samples were stored at $-20^{\circ} \mathrm{C}$ for subsequent analysis.

\section{Detection of SNPs and genotyping}

Primers used to amplify cattle the promoter of bovine TLR4 gene were designed by Primer5 software, according to the published gene sequence (GenBank acc. no. AC_000165). Primers, restriction enzymes selected (ABI, Foster City, CAUSA) and fragment sizes were listed in Table 1. The detection results of allelic variation were based on the electrophoretic pattern of the restriction enzyme-treated $P C R$ products.

PCR amplifications were performed in a total volume of $20 \mu \mathrm{L}$, where the volume mixture contained: $50 \mathrm{ng}$ of genomic DNA as template, $2 \mu \mathrm{L} 10 \times \mathrm{PCR}$ buffer ( $\mathrm{Mg}^{2+}$ plus), $0.25 \mu \mathrm{M}$ of each primer, $0.25 \mu \mathrm{M}$ of each dNTP and $2.0 \mathrm{U}$ Tap DNA polymerase (MBI Fermentas, Amherst, NY, USA). PCR conditions were as follows: after an initial denaturation of $5 \mathrm{~min}$ at $95^{\circ} \mathrm{C}$ amplicons were generated for 35 cycles of $30 \mathrm{~s}$ at $94^{\circ} \mathrm{C}, 30 \mathrm{~s}$ at an optimal annealing temperature, and $45 \mathrm{~s}$ at $72^{\circ} \mathrm{C}$, followed by a $10 \mathrm{~min}$ final extension at $72^{\circ} \mathrm{C}$.

Restriction fragment length polymorphism analysis was used to identify the genotypes of SNPs. The PCR products were digested in a total volume of $10 \mu \mathrm{L}$ containing: $5 \mu \mathrm{L}$ of PCR product, three units of restriction enzyme $(0.3 \mu \mathrm{L}), 1 \mu \mathrm{L}$ of reaction buffer and $3.7 \mu \mathrm{L}$ of $\mathrm{ddH}_{2} \mathrm{O}$. The mixture was incubated for $10 \mathrm{~h}$ at specific temperature ( $\mathrm{Bg} / \mathrm{l}$ and $\mathrm{Msp} /$ restriction enzymes were digested 
at $37^{\circ} \mathrm{C}$, respectively). Digested PCR products were mixed with $10 \times$ loading buffer and subjected to $2.5 \%$ agarose gel electrophoresis in $1 \times$ TBE at constant voltage $(110 \mathrm{~V})$ for $1.0 \mathrm{~h}$ at room temperature. Individuals were then genotyped based on different electrophoresis patterns. Fragments displaying different PCR-RFLP patterns were purified with Qiaquick spin columns (Qiagen, Hilden, Germany) and sequenced with the ABI PRISM 3730 sequencer (ABI, Foster City, CA, USA) and sequences were analyzed with BioXM software v2.6 (Biomax Informatics AG, Munich, Germany). The sequences obtained were named with letters of the alphabet.

\section{Statistical analysis}

To investigate the effects of the promoter of TLR4 gene genotypes on SCS and milk production traits, the general linear models (GLM) was used with the procedure of SPSS software v16 (SPSS Inc., Chicago, IL, USA) (Holzer \& Precht 1992, Chen et al. 2013). The following linear model was applied:

$$
Y_{i j k l m n}=\mu+F_{i}+G_{j}+S_{k}+E_{l}+H_{m}+e_{i j k l m n}
$$

where $Y_{i j k m n}$ is the observed value, $\mu$ is the overall mean, $F_{i}$ is the fixed effect of the farm, $G_{j}$ is the fixed effect of the genotype, $S_{k}$ is the fixed effect of sire, $E_{l}$ is the fixed effect of the season, $H_{m}$ is the fixed effect of parity, and $e_{i j k l m n}$ is the random residual effect. A value of $P<0.05$ was regarded as significant after Bonferroni correction for multiple testing.

\section{Results}

In the present study, Genomic DNA of Chinese Holstein breed was successfully amplified using primer pairs for the promoter of TLR4 gene (Table 1).

Table 1

Primers and annealing temperatures used for PCR-RFLP analysis of the TLR4 promoter

\begin{tabular}{llccll}
\hline Primers & Sequences of primers and Position & AT, $^{\circ} \mathrm{C}$ & SAF, bp & Methods & Restriction enzyme \\
\hline SNP1 & 5'- TTC TTC AAC CCA ACC CAC CT -3' & 56 & 546 & PCR-RFLP & Bgll \\
SNP2 & 5'- GCC CTG GCT CAC CAC AAC TA -3' & & & & \\
& 5'- GGG TAT TTT GTT ATG GCT GG -3' & 54.5 & 477 & PCR-RFLP & Msp I \\
\hline
\end{tabular}

AT: annealing temperature, SAF: size of amplification fragment

In total, two variants were identified in the study (Figure 1 and Table 2). PCR-RFLP was used to genotype the individuals. According to the sequence mutations, the PCR products could be digested with Bgll and Mspl restriction enzymes. The genotypes observed for the two SNPs were illustrated in Figure 2. Genetics diversity parameters including allele and genotype frequencies, Chi-square test, effective number of allele ( $\mathrm{Ne})$, heterozygosity ( $\mathrm{He})$, homozygosity and polymorphism information content (PIC) were calculated and summarized in Table 2. According to Table 2, SNP1 agreed with Hardy-Weinberg disequilibrium $(P>0.05)$, SNP2 did not agree with Hardy-Weinberg disequilibrium $(P<0.05)$. According to the genetic diversity classification of PIC (PIC value $<0.25$, low polymorphism; $0.25<$ PIC value $<0.5$, intermediate polymorphism and PIC value $<0.5$, high polymorphism), Two SNPs were moderate polymorphic loci which inferred the selection potential of the two loci were abundant. 


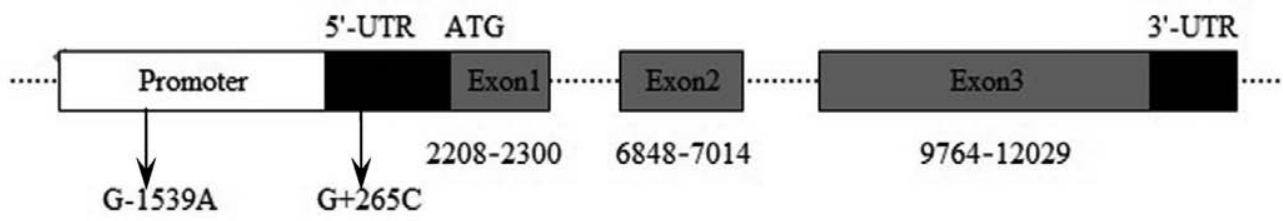

Gray boxes represent the exons. Black boxes represent the untranslated regions. Blank box represents the promoter. Dotted lines represent the introns. Number represents the nucleotide sequence position relative to the reference sequence. G-1539A and G+265C are two SNPs found in the bovine TLR4 gene.

Figure 1

Genomic sequences of the bovine TLR4 gene (AC_000165)

Table 2

Genotypic and allelic frequencies (\%), value of $\mathrm{x} 2$ test and diversity parameter of the promoter of bovine TLR4 gene

\begin{tabular}{lccccccccc}
\hline Loci & Genotype & Genotype no. & GF & Allele & AF & $X^{2}(\mathrm{HWE})$ & He & Ne & PIC \\
\hline G-1539A & GG & 219 & 52.12 & G & 71.45 & $P>0.05$ & 0.4080 & 1.6891 & 0.3248 \\
& GA & 163 & 38.65 & A & 28.55 & & & & \\
& AA & 39 & 9.23 & & & & & & \\
G+265C & GG & 146 & 34.58 & G & 61.45 & $P<0.05$ & 0.4738 & 1.9003 & 0.3615 \\
& GC & 226 & 53.74 & C & 38.55 & & & & \\
& CC & 49 & 11.68 & & & & & & \\
\hline
\end{tabular}

GF: genotypic frequency, AF: allelic frequency, $X^{2}(\mathrm{HWE})$ : Hardy-Weinberg equilibrium $X^{2}$ value, He: gene heterozygosity, Ne: effective allele, PIC: polymorphism information content
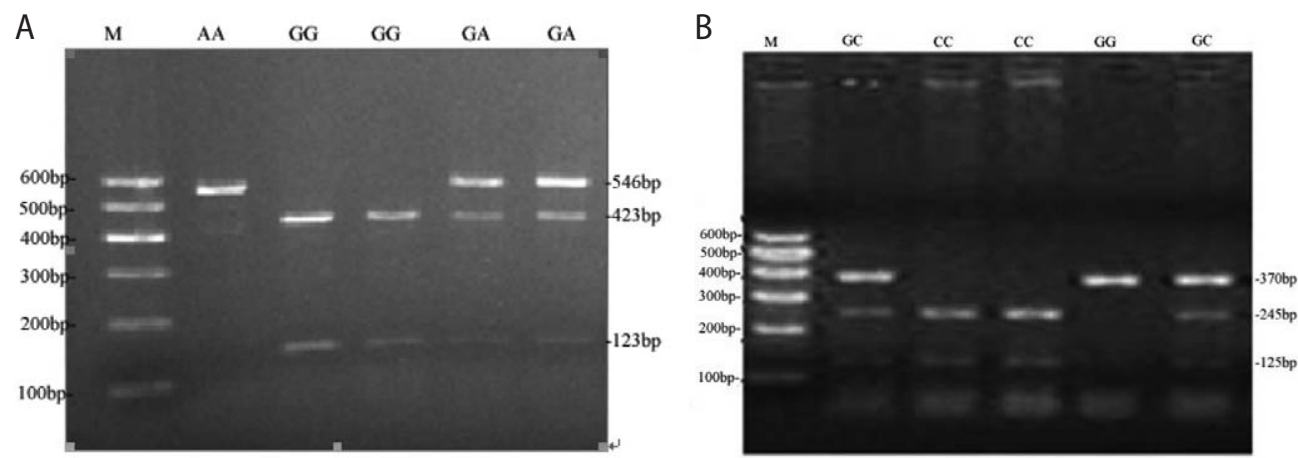

(A) The $2.5 \%$ agarose gels electrophoretic patterns of the promoter of TLR4 gene.

$\mathrm{M}=\mathrm{DNA}$ molecular weight marker is Marker I; G-1539A genotype: $\mathrm{AA}=546 \mathrm{bp}, \mathrm{GG}=423 \mathrm{bp}+123$

bp, $\mathrm{GA}=546 \mathrm{bp}+423 \mathrm{bp}+123 \mathrm{bp}$.

(B) The $2.5 \%$ agarose gels electrophoretic patterns of the promoter of $T L R 4$ gene.

$\mathrm{M}=\mathrm{DNA}$ molecular weight marker is Marker I; $\mathrm{G}+265 \mathrm{C}$ genotype: $\mathrm{GC}=370 \mathrm{bp}+245 \mathrm{bp}+125$

$b p+65 b p+42 b p, C C=245 b p+125 b p+65 b p+42 b p, G G=370 b p+65 b p+42 b p$. It is difficult to

see the $65 \mathrm{bp}$ and $42 \mathrm{bp}$ DNA fragment on $2 \%$ agarose gel.

Figure 2

PCR-RFLP detection results of the promoter of TLR4 gene PCR product 
The results of the association analyses between two mutations in the promoter of TLR4 gene and milk production traits and SCS were shown in Table 3. According to Table 3, at locus G-1539A, the animals with the GG genotype had much higher 305 days milk yield than those with the AA genotype $(P<0.01)$. At locus $\mathrm{G}+265 \mathrm{C}$, the animals with the $\mathrm{GC}$ genotype had a smaller SCS than those with the CC genotype $(P<0.05)$. The rest of the records of milk production traits and SCS had no significant association $(P>0.05)$. The result suggested that the SNP could be functional affecting the level of TLR4 mRNA and protein expression as previously reported (Pottier et al. 2007).

Table 3

Milk production traits and SCS for different genotypes in Chinese Holstein cows $(n=421)$

\begin{tabular}{lcccccc}
\hline Loci & Genotypes & Genotype no. & $\begin{array}{c}305 \text { days milk yield, kg } \\
\text { (mean } \pm \text { SE) }\end{array}$ & $\begin{array}{c}\text { Fat rate, \% } \\
\text { (mean } \pm \text { SE) }\end{array}$ & $\begin{array}{c}\text { Protein rate, } \% \\
\text { (mean } \pm \text { SE) }\end{array}$ & $\begin{array}{c}\text { SCS } \\
\text { (mean } \pm \text { SE) }\end{array}$ \\
\hline G-1539A & GG & 219 & $8147.37 \pm 159.68^{\mathrm{A}}$ & $3.69 \pm 0.05$ & $2.94 \pm 0.03$ & $3.94 \pm 0.30$ \\
& GA & 163 & $7960.64 \pm 202.80^{\mathrm{AB}}$ & $3.54 \pm 0.57$ & $2.99 \pm 0.04$ & $3.91 \pm 0.37$ \\
& $\mathrm{AA}$ & 39 & $7635.22 \pm 386.72^{\mathrm{B}}$ & $3.72 \pm 0.57$ & $2.96 \pm 0.11$ & $3.61 \pm 0.68$ \\
& $\mathrm{P}$ & & 0.009 & 0.601 & 0.840 & 0.188 \\
$\mathrm{G}+265 \mathrm{C}$ & $\mathrm{GG}$ & 146 & $7886.72 \pm 210.11$ & $3.70 \pm 0.06$ & $2.97 \pm 0.05$ & $3.58 \pm 0.32^{\mathrm{ab}}$ \\
& $\mathrm{GC}$ & 226 & $7818.65 \pm 203.89$ & $3.62 \pm 0.05$ & $2.97 \pm 0.03$ & $3.39 \pm 0.30^{\mathrm{b}}$ \\
& $\mathrm{CC}$ & 49 & $7663.42 \pm 373.33$ & $3.48 \pm 0.13$ & $2.83 \pm 0.03$ & $3.83 \pm 0.61^{\mathrm{a}}$ \\
& $\mathrm{P}$ & & 0.175 & 0.515 & 0.230 & 0.038 \\
\hline
\end{tabular}

Values with different superscripts within the same column differ significantly at ${ }^{\mathrm{a}, \mathrm{b}} P<0.05$ and ${ }^{\mathrm{AB}} P<0.01$.

\section{Discussion}

This study suggests significant association of the promoter of TLR4 gene genetic variation in determining bovine's SCS and milk production traits. The genetic variation we found could be used as molecular marker for the selection of animals with optimizing production traits. Moreover, further work is needed in the large population or other cattle breeds to confirm the associations we found along with functional analysis such as RNA interference (RNAi) and overexpression study to understand the regulation mechanisms of the promoter of TLR4 gene on animal production traits. Consider overall, this work provides the insights that variations in production traits could be used as molecular marker for the selecting breeding of Chinese Holstein cattle in China.

\section{Acknowledgements}

This study was supported by the National 863 Program of China (No. 2008AA101010) and (No. 2011AA100307), »13115« Sci-Tech Innovation Program of Shaanxi Province (No. 2008ZDKG-11).

\section{References}

Chen RJ, Wang ZZ, Yang ZP, Mao YJ, Ji DJ, Zhu XR, Hamza AE (2013) A novel SNP of lysozyme gene and its association with mastitis trait in Chinese Holstein. Arch Tierz 56, 058

Goldammer T, Zerbe H, Molenaar A, Schuberth HJ, Brunner RM, Kata SR, Seyfert HM (2004) Mastitis Increases Mammary mRNA Abundance of â-Defensin 5, Toll-Like-Receptor 2 (TLR2), and TLR4 but Not TLR9 in Cattle. Clin Vaccine Immunol 11, 174-185 
Holzer C, Precht M (1992) Multiple comparison procedures for normally distributed ANOVA models in SAS, SPSS, BMDP, and MINITAB. Comput Stat Data Anal 13, 351-358

Pottier N, Cheok MH, Yang W, Assem M, Tracey L, Obenauer JC, Panetta JC, Relling MV, Evans WE (2007) Expression of SMARCB1 modulates steroid sensitivity in human lymphoblastoid cells: identification of a promoter snp that alters PARP1 binding and SMARCB1 expression. Hum Mol Genet 16, 2261-2271

Ruegg PL (2003) Investigation of mastitis problems on farms. Vet Clin North Am Food Anim Pract 19, 47-73

Seegers H, Fourichon C, Beaudeau F (2003) Production effects related to mastitis and mastitis economics in dairy cattle herds. Vet Res 34, 475-491

Werling D, Jungi TW (2003) TOLL-like receptors linking innate and adaptive immune response. Vet Immunol Immunopathol 91, 1-12

White SN, Kata SR, Womack JE (2003) Comparative fine maps of bovine toll-like receptor 4 and toll-like receptor 2 regions. Mamm Genome 14, 149-155 